\title{
Socioeconomic and demographic factors determining the underweight prevalence among children under-five in Punjab
}

\author{
Rizwan Farooq ${ }^{1}$, Hina Khan ${ }^{2 *}$, Masood Amjad Khan² and Muhammad Aslam³
}

\begin{abstract}
Background: Underweight prevalence continues to be major public health challenge worldwide, particularly in developing countries like Pakistan. This study is focused on socio-economic and demographic aspects of underweight prevalence among children under-five in Punjab.
\end{abstract}

Methods: In this study, several socioeconomic and demographic factors are considered using MICS-4 data-set. Only those variables which are usually described in the nutritional studies of children were picked. Covariates include: the age of children, sex of the children, age of mother, total number of children born to women, family wealth index quintile, source of drinking water, type of sanitation, place of residence, parents' education and occupation. All Categorical variables are effect coded. The child's age and the mother's age are assumed to be nonlinear, geographical region is spatial effect, while other variables are parametric in nature.

Since, the response is binary, covariate comprises linear terms, nonlinear effects of continues covariates and geographic effects, so we have use Geo-additive models (based on Fully Bayesian approach) with binomial family under logit link. Statistical analysis is performed on Statistical package R using Bayes X and R2 Bayes X Libraries.

Results: Underweight status of children was found to be positively associated with number of under-five children in household, total number of children ever born to women and age of mother when the child was born. Whereas, it negatively associated with place of residence, parent's education and family wealth index quintile. On the regional effect, the Southern Punjab has higher prevalence of underweight compared to Central and Northern Punjab.

Conclusion: Similarity of our results with several other studies demonstrate that the Geo-additive models are an ideal substitute of other statistical models to analyze the underweight prevalence among children. Moreover, our findings suggest the Punjab Government, to introduce target-oriented programs such as poverty reduction and enhancement of education and health facilities for poor population and disadvantaged regions, especially Southern Punjab.

Keywords: Bayes X, Fully Bayesian approach, Geo-additive models, Locality, Markov chain Monte Carlo, Stunting, Underweight, Wealth index quintile, Wasting

\section{Background}

Underweight prevalence is a major cause of child mortality worldwide. Underweight children have lesser immunity against infections and have higher chance to die

\footnotetext{
* Correspondence: hinakhan@gcu.edu.pk

²Department of Statistics, GC University Lahore, Lahore, Pakistan

Full list of author information is available at the end of the article
}

from common diseases, and those who survive are exposed to recurring illnesses and slower growth. Such children are more likely to have lower IQ, which not only affect their educational performance but also reduce their working abilities $[1,2]$.

According to MICS-2014 [1], the prevalence of underweight among under-five children in Punjab is 33.7\%,

C C The Author(s). 2020 Open Access This article is licensed under a Creative Commons Attribution 4.0 International License, which permits use, sharing, adaptation, distribution and reproduction in any medium or format, as long as you give appropriate credit to the original author(s) and the source, provide a link to the Creative Commons licence, and indicate if changes were made. The images or other third party material in this article are included in the article's Creative Commons licence, unless indicated otherwise in a credit line to the material. If material is not included in the article's Creative Commons licence and your intended use is not permitted by statutory regulation or exceeds the permitted use, you will need to obtain permission directly from the copyright holder. To view a copy of this licence, visit http://creativecommons.org/licenses/by/4.0/ The Creative Commons Public Domain Dedication waiver (http://creativecommons.org/publicdomain/zero/1.0/) applies to the data made available in this article, unless otherwise stated in a credit line to the data. 
which is higher than the overall the underweight prevalence in the country (Fig. 1). It is a point of serious concern, because Punjab is comparatively most developed province of Pakistan regarding health and educational facilities. Additionally, it is also the most densely populated province of country, so a minor change in the percentage can be of greater significance. Therefore, a question arises what are the factors behind such a high rate of underweight prevalence among children in the province.

To the best of our knowledge, not even a single research study has been conducted in Punjab so far, to explore and analyze the impact of factors influencing such a high proportion of underweight.

Alasfoor et al. (2007), Mengistu et al. (2013) and Rayhan et al. (2006), use bivariate and multivariate analysis to identify the causes of under-five malnutrition [5-7]. The key factors for under-five malnourishment were the education level of parents, income of the household and total number of under-five children in household. Sapkota \& Gurung (2009) and Wolde et al. (2014) used logistic regression techniques to calculate the underweight prevalence among children under-five [8-10]. They discovered that the socioeconomic status of family, maternal education and gender, ethnicity and age of children were closely linked with underweight prevalence. Some other authors [11-16] found that age and gender of children, child's malaria status, exclusive breastfeeding, child's vaccination status, maternal education, parent's access to media, ARI in children, poverty and the type of toilet used in household were strongly correlated with underweight.

Majority of previous studies on child's underweight have usually focused on different socio-economic, demographic or health related factors but mostly have ignored spatial and nonlinear effects of covariates. Considering these aspects, Kandala et al. (2008), Lasisi et al. (2014) and Lasisi et al. (2014) use Bayesian geo-additive models to observe the pattern of underweight among the children under five year of age [14, 17, 18]. Their studies showed that underweight among children depends on residence, age of the child, maternal education, wealth status of the household and geographical zone.

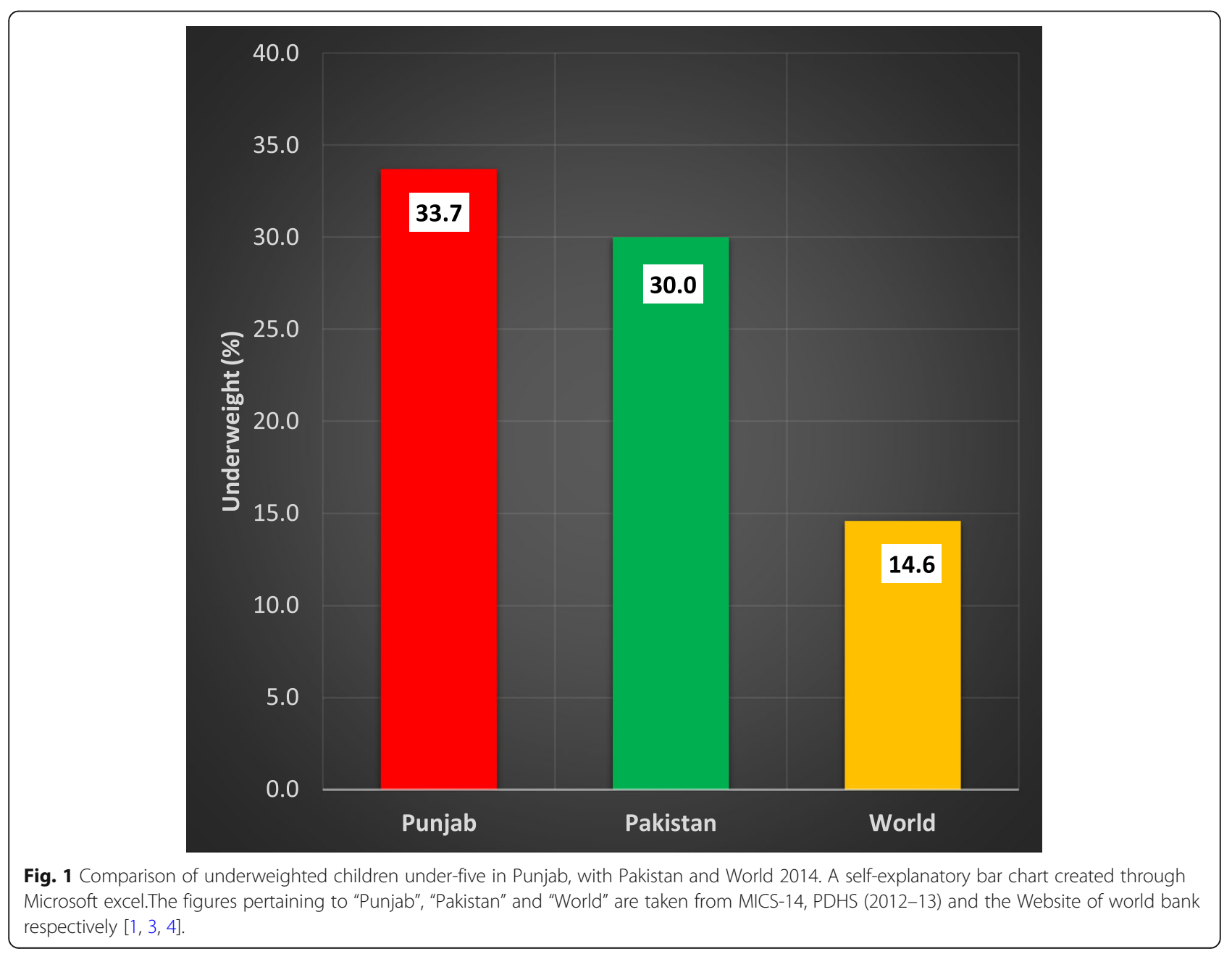


Table 1 Association between underweight and socioeconomic and demographic variables

\begin{tabular}{|c|c|c|c|c|c|c|}
\hline \multirow[t]{2}{*}{ Covariate } & \multirow[t]{2}{*}{ Categories } & \multicolumn{2}{|l|}{ Underweight } & \multicolumn{3}{|c|}{ Pearson Chi- Square Test } \\
\hline & & No (\%) & Yes (\%) & Value & d.f & $P$-Value \\
\hline \multirow[t]{2}{*}{ Locality } & Rural & $10,095(62.90)$ & $5954(37.10)$ & 189.35 & 1 & 0.000 \\
\hline & Urban & $5915(71.74)$ & $2330(28.26)$ & & & \\
\hline \multirow[t]{2}{*}{ Gender } & Female & $8153(65.74)$ & $4248(34.26)$ & 0.276 & 1 & 0.607 \\
\hline & Male & $7857(66.06)$ & $4036(33.94)$ & & & \\
\hline \multirow[t]{5}{*}{ Mother's education level } & None & $6880(43.68)$ & $4998(56.32)$ & 931.495 & 4 & 0.000 \\
\hline & Primary & $2975(66.08)$ & $1527(33.92)$ & & & \\
\hline & Middle & $1695(71.88)$ & $663(28.12)$ & & & \\
\hline & Secondary & $2209(76.12)$ & $693(23.88)$ & & & \\
\hline & Higher & $2251(84.82)$ & $403(15.18)$ & & & \\
\hline \multirow[t]{5}{*}{ Father's education level } & None & $3848(55.39)$ & $3099(44.61)$ & 810.205 & 4 & 0.000 \\
\hline & Primary & $2772(61.72)$ & $1719(38.28)$ & & & \\
\hline & Middle & $2729(67.27)$ & $1328(32.73)$ & & & \\
\hline & Secondary & $3877(51.98)$ & $1456(27.30)$ & & & \\
\hline & Higher & $2784(80.01)$ & $682(19.99)$ & & & \\
\hline \multirow[t]{2}{*}{ Mother's occupation } & Housewife & $14,345(66.27)$ & $7300(33.73)$ & 12.285 & 1 & 0.000 \\
\hline & Working Woman & $1665(62.85)$ & $984(37.15)$ & & & \\
\hline \multirow[t]{5}{*}{ Father's occupation } & Unemployed & $836(68.36)$ & 387 (31.64) & 324.201 & 4 & 0.000 \\
\hline & Laborer & $3606(13.33)$ & $2667(42.52)$ & & & \\
\hline & Farmer & $2488(92.58)$ & $1407(36.12)$ & & & \\
\hline & Official & $4800(36,24)$ & $2065(30.08)$ & & & \\
\hline & Businessman & $4280(79.50)$ & $1758(29.12)$ & & & \\
\hline \multirow[t]{5}{*}{ Wealth index quantile } & Lowest & $2981(52.44)$ & $2704(47.56)$ & 1076.13 & 4 & 0.000 \\
\hline & Second & $3137(61.11)$ & $1996(38.89)$ & & & \\
\hline & Middle & $3374(67.64)$ & $1614(32.36)$ & & & \\
\hline & Fourth & $3484(72.09)$ & $1349(27.91)$ & & & \\
\hline & Highest & $3034(83.01)$ & $621(16.99)$ & & & \\
\hline Total number of under-five children in household & None & $16,010(65.90)$ & $8284(34.10)$ & 22.077 & 8 & 0.040 \\
\hline Total children ever born to a woman & None & $15,997(65.90)$ & $8276(34.10)$ & 192.48 & 17 & 0.000 \\
\hline \multirow[t]{2}{*}{ Sanitation } & Unimproved & $4723(57.08)$ & $3551(42.92)$ & 434.23 & 1 & 0.000 \\
\hline & Improved & $11,287(70.46)$ & $4733(29.54)$ & & & \\
\hline \multirow[t]{2}{*}{ Sources of drinking water } & Unimproved & $850(62.32)$ & $514(37.68)$ & 7.1 & 1 & 0.008 \\
\hline & Improved & $15,098(65.84)$ & $7832(34.16)$ & & & \\
\hline \multirow[t]{2}{*}{ Access to media } & No & $5030(58.08)$ & $3630(41.92)$ & 366.011 & 1 & 0.000 \\
\hline & Yes & $10,980(70.23)$ & $4654(29.77)$ & & & \\
\hline \multirow[t]{3}{*}{ Region } & Southern Punjab & $5029(60.10)$ & $3339(39.90)$ & 264.389 & 2 & 0.000 \\
\hline & Central Punjab & $9491(67.76)$ & $4516(32.24)$ & & & \\
\hline & Northern Punjab & $1489(77.63)$ & $429(23.37)$ & & & \\
\hline Age of mother when children born & None & $16,010(65.90)$ & $8284(34.10)$ & 54.538 & 38 & 0.0400 \\
\hline Age of children & None & $16,010(65.90)$ & $8284(34.10)$ & 140.544 & 59 & 0.000 \\
\hline
\end{tabular}

\section{Methods}

We aim to study the impact of several socioeconomic and demographic factors on underweight status of under-five children in Punjab, considering the spatial and nonlinear effects of covariates. This study is based on data-set of the MICS-2014 conducted by Punjab Bureau of Statistics with the collaboration of UNICEF. 
Table 2 Parametric coefficients

\begin{tabular}{|c|c|c|c|c|c|c|}
\hline \multicolumn{2}{|l|}{ Co-efficient } & $\operatorname{Mean}(\gamma)$ & Sd & $2.50 \%$ & $50 \%$ & $97.50 \%$ \\
\hline \multicolumn{2}{|l|}{ (Intercept) } & -0.2324 & 0.1096 & -0.4543 & -0.2308 & -0.0123 \\
\hline Locality & Urban & -0.1254 & 0.039 & -0.0478 & -0.1256 & -0.2026 \\
\hline \multirow[t]{4}{*}{ Mother's education level } & Primary & -0.0814 & 0.0403 & -0.1654 & -0.0809 & -0.0042 \\
\hline & Middle & -0.1904 & 0.0543 & -0.2979 & -0.19 & -0.0851 \\
\hline & Secondary Secondary & -0.2502 & 0.0569 & -0.3635 & -0.2505 & -0.139 \\
\hline & Higher & -0.5868 & 0.0722 & -0.7318 & -0.5849 & -0.446 \\
\hline \multirow[t]{4}{*}{ Father's education level } & Primary & -0.0892 & 0.0419 & -0.1725 & -0.0898 & -0.0045 \\
\hline & Middle & -0.173 & 0.0444 & -0.2571 & -0.1741 & -0.0857 \\
\hline & Secondary & -0.2824 & 0.0443 & -0.3705 & -0.2829 & -0.196 \\
\hline & Higher & -0.4105 & 0.0616 & -0.5269 & -0.4119 & -0.2849 \\
\hline Mother's occupation & Working_woman & 0.025 & 0.0458 & -0.0633 & 0.0269 & 0.1144 \\
\hline \multirow[t]{4}{*}{ Father's occupation } & Laborer & 0.1637 & 0.0703 & 0.025 & 0.1635 & 0.3027 \\
\hline & Farmer & -0.0581 & 0.0734 & -0.2078 & -0.0583 & 0.0865 \\
\hline & Official & 0.084 & 0.0698 & -0.0547 & 0.0855 & 0.2174 \\
\hline & Businessman & 0.0069 & 0.0712 & -0.1376 & 0.0086 & 0.1499 \\
\hline \multirow[t]{4}{*}{ Wealth index quantile } & Second & -0.1842 & 0.0441 & -0.2677 & -0.1838 & -0.0974 \\
\hline & Middle & -0.3471 & 0.0533 & -0.4508 & -0.3467 & -0.2429 \\
\hline & Fourth & -0.4489 & 0.0636 & -0.5748 & -0.45 & -0.3224 \\
\hline & Highest & -0.8336 & 0.0837 & -1.0036 & -0.8334 & -0.6657 \\
\hline \multicolumn{2}{|c|}{ Total number of under-five children in household } & 0.0138 & 0.0137 & -0.0128 & 0.0135 & 0.0402 \\
\hline \multicolumn{2}{|c|}{ Total children ever born to a woman } & 0.0392 & 0.0088 & 0.022 & 0.0391 & 0.0566 \\
\hline Sanitation & Improved & -0.0894 & 0.0362 & -0.1579 & -0.0899 & -0.0181 \\
\hline Sources of drinking water & Improved & -0.0261 & 0.0657 & -0.1507 & -0.0274 & 0.1076 \\
\hline Access to media & Yes & -0.024 & 0.0329 & -0.0886 & -0.0234 & 0.0418 \\
\hline \multirow[t]{2}{*}{ Region } & Central Punjab & -0.3928 & 0.0643 & -0.5236 & -0.3912 & -0.27 \\
\hline & Northern Punjab & -0.0868 & 0.0311 & -0.1458 & -0.0875 & -0.024 \\
\hline
\end{tabular}

Two-stage cluster sampling technique was used for selection of sample. At first stage 2050 clusters were randomly selected (called primary sampling units) from all 36 districts of Punjab through proportional allocation. On second stage systematic sample of 20 households (Called secondary sampling units) was randomly drawn from each of selected cluster [1]. The information about one or more explanatory variable(s) used in this study was missing for 6789 out of 31,083 children interviewed, so these were discarded. Finally, the total sample size for the research is 10,774 women of reproductive age (15-49) in Gilgit Baltistan.
Underweight status of children $(U W a)$, i.e. weight-for-age" is taken as a dependent variable. In this regard, the weight and the height of each child in sample is calculated separately. These measures are then expressed as Z-scores from the median of the reference population.

$$
\mathrm{Z}_{\mathrm{i}}=\frac{\mathrm{WAP}_{\mathrm{i}-} \mu_{\mathrm{WAP}}}{\sigma_{\mathrm{WAP}}}
$$

Where, WAP $\mathrm{WA}_{\mathrm{i}}$ is the weight for age percentile of $i_{t h}$ child, while $\mu_{\mathbf{W A P}}$ and $\sigma_{\mathrm{WAP}}$ denote the median and standard deviation of WAP of reference population

Table 3 Smooth terms variances

\begin{tabular}{|c|c|c|c|c|c|c|c|}
\hline Smooth Terms & Mean & Sd & $2.50 \%$ & $50 \%$ & $97.50 \%$ & Min & Max \\
\hline Age of children & 0.0209 & 0.0617 & 0.0005 & 0.0054 & 0.1284 & 0.0001 & 2.2943 \\
\hline Age of mother when children born & 0.0028 & 0.0593 & 0.0003 & 0.001 & 0.0062 & 0.0001 & 2.6521 \\
\hline
\end{tabular}




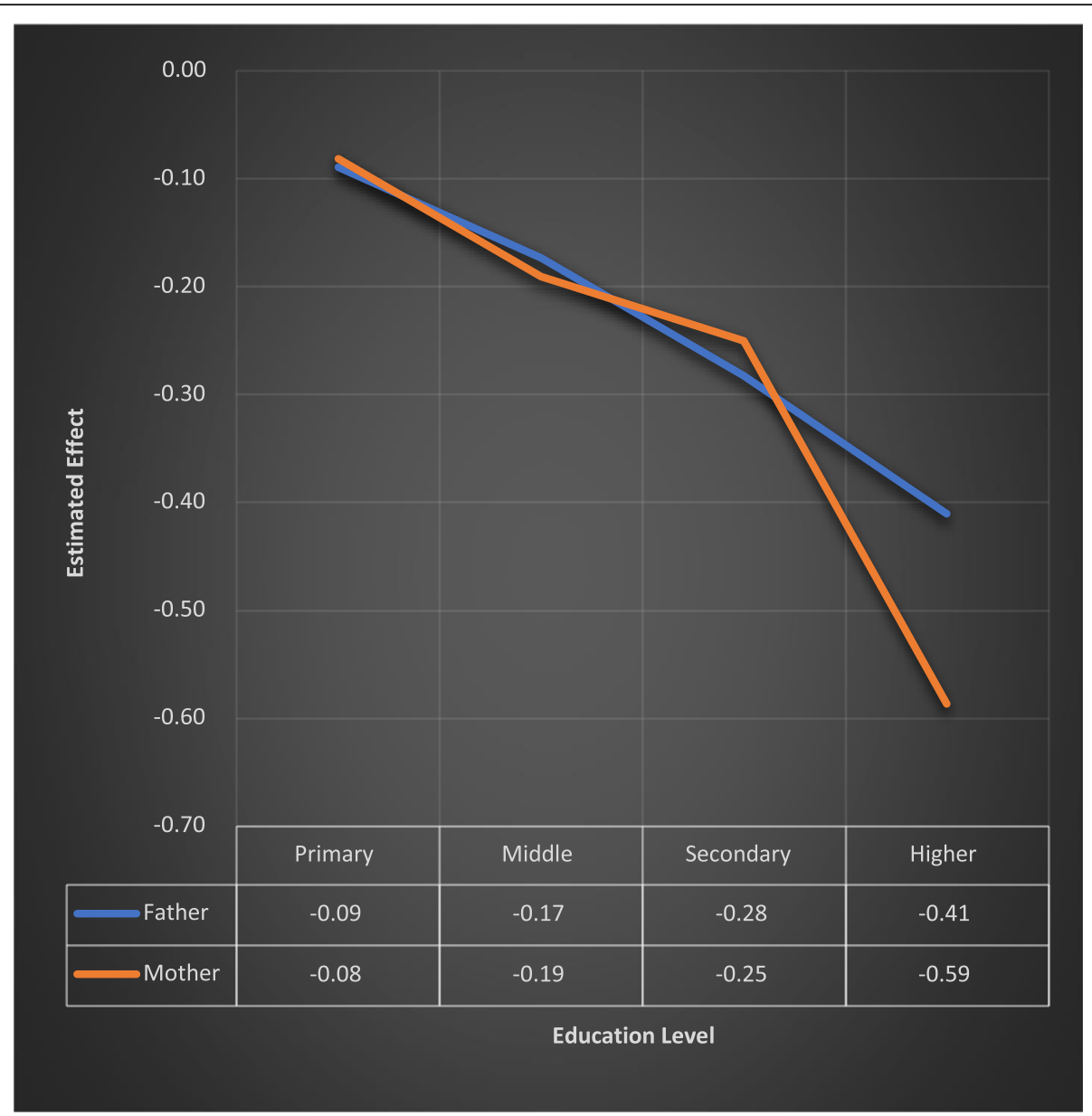

Fig. 2 Comparison of Effect of Education Level of Mother" and Father" of Children on Underweight. A line chart developed through Microsoft excel to see the effect of education level of mother and father on underweight status of under-five children in Punjab province of Pakistan. Estimated effect is corresponding value of regression coefficient for each level of education

respectively. A child $i$ ' is declared as an underweight if $Z_{i}<-2$, else Normal weight. So, our response variable $(U W a)$ is binary with 0 \& 1 refers to Normal weight and underweight children respectively.

We consider several socio-economic and demographic covariates as predictor, which are generally described in the nutritional studies of children. Covariates include; the age of children, sex of the children, age of mother, total number of children ever born to women, family wealth index quintile, source of drinking water, type of sanitation, place of residence (locality), parents' education and occupation. All categorical variables are effect coded; Children's age and Mother's age (when child born) are assumed nonlinear; Region" is geographic effect, while other covariates are parametric in nature (Additional file 1).

\section{Statistical analysis}

Since, our response is binary; covariates consist of usual linear terms, nonlinear effects of continuous covariates and geographic effects, such sort of models are called Geo-Additive Regression Models, which are special case of Structure Additive Regression Models. We use GeoAdditive Regression under logit link, because we are interested to find the relative risk of underweight at different levels of given covariates. For inference, we have used a Fully Bayesian Approach because we want to describe them probabilistically. In this approach, all unknown regression coefficients and the smoothing functions are considered as random variables and must be assigned with appropriate prior distributions (Additional file 2). This methodology is based on Markov priors and uses Markov Chain Monte Carlo techniques to draw samples from posterior, and for model checking it normally used the Deviance Information Criterion. For detail, see [19-22].

Statistical analysis is performed on $\mathrm{R}$ Language using BayesX and R2BayesX Libraries (Additional file 2). 


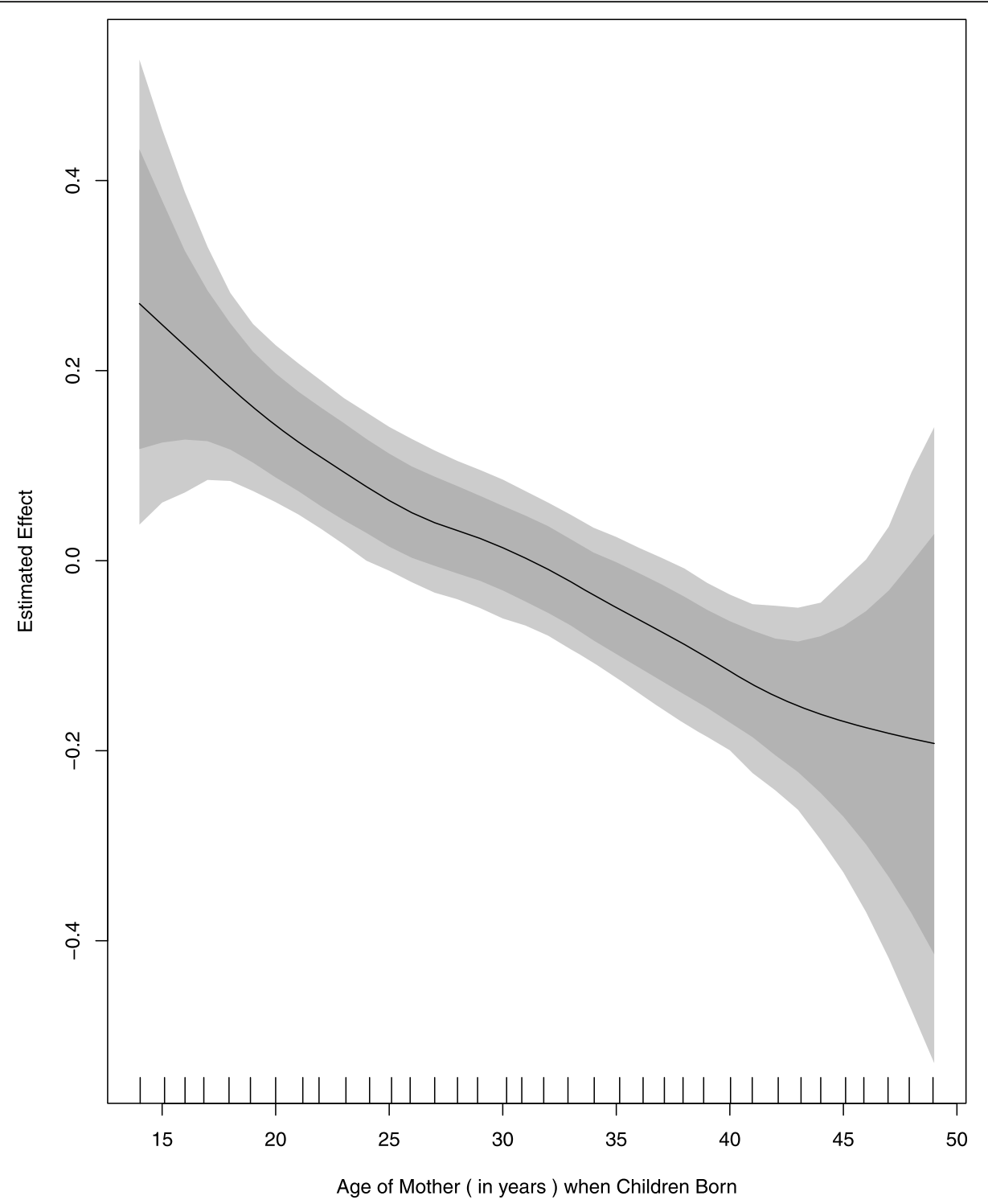

Fig. 3 Effect of Mother Age when Children Born (In Years)" on Underweight. A Built-in function of BayesX package in R language (based on smooth term "sx (MACB)", provided in Table 3), wherein Estimated Effect of Covariate "Mother Age when Children Born" i.e. "f (MACB)" is plotted against corresponding values of covariates

\section{Results}

Before executing the final model, a bivariate analysis was performed, in order to decide which variables were to be included in the final model. The association between underweight status of children and different socio-economic and demographic variables (based on Pearson Chi-square tests of independence at $5 \%$ level of significance) is given in Table 1. According to Table 1, All variables, except the gender of children, found significantly associated with the underweight status of children. It is, therefore, the gender of children is discarded from final model (Additional file 2).
Model summary for our final model (with 20,000 iterations, burnin $=0$, step $=10$, family $=$ binomial, link $=$ logit) is given in Table 2 and Table 3 (Additional file 2) (Fig. B1) (Fig. B2).

According to summary of results (Table 2), going from rural to urban areas decreases the log odds of underweight by 0.13 .

Underweight status of Children under-five in Punjab is negatively associated with education level of father and mother of children. The log odds of underweight decreased by $0.09,0.17,0.28$ and 0.41 for children whose fathers attain primary, middle, secondary and higher level of education respectively w.r.t. those having no education at 


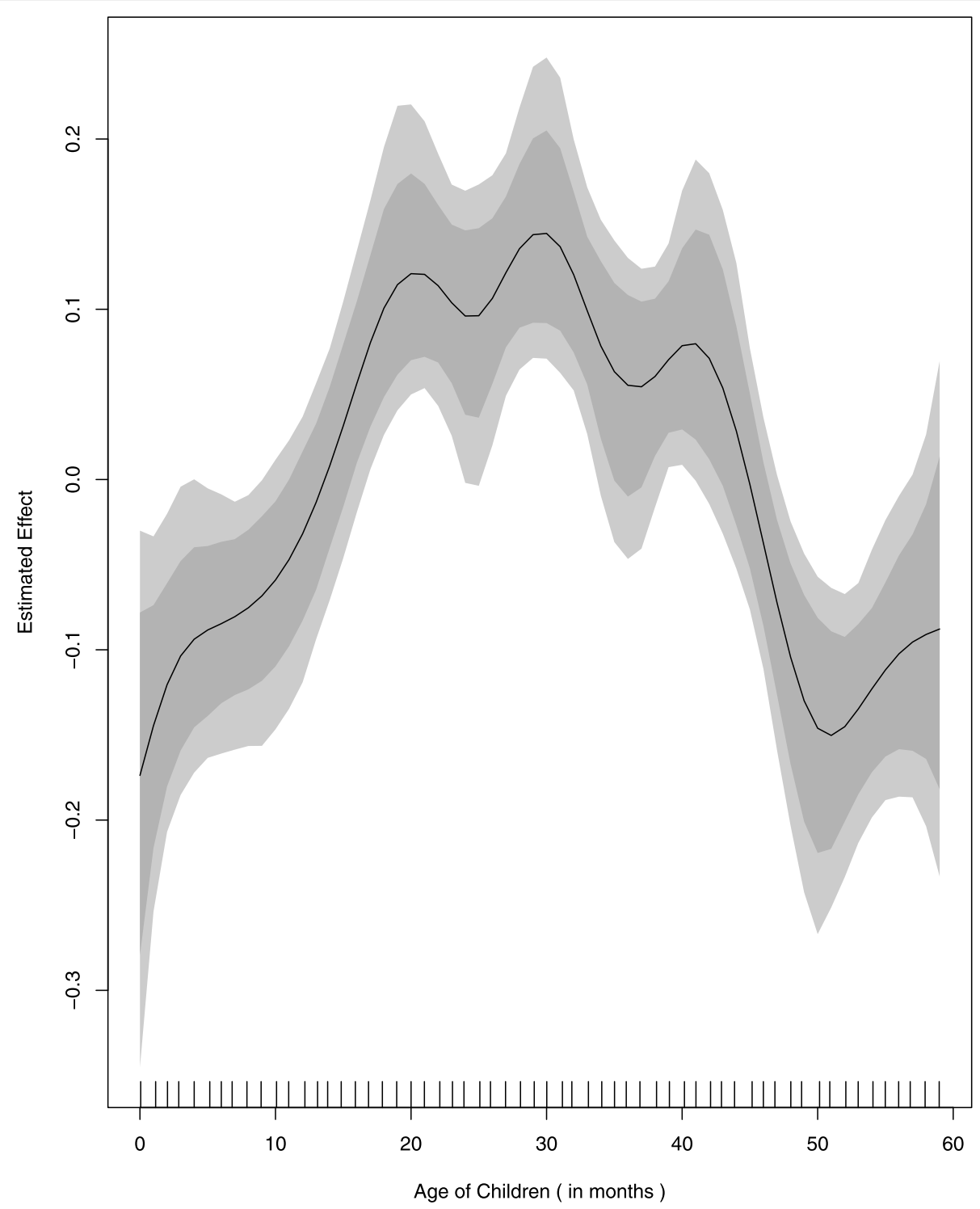

Fig. 4 Effect of Children Age (In Months)" on Underweight.A Built-in function of BayesX package in R language (based on smooth term "sx(CAGE)", provided in Table 3), wherein Estimated Effect of Covariate "Age of children in months" i.e. "f (CAGE)"is plotted against corresponding values of covariates

Table 4 Wealth index quintile

\begin{tabular}{|c|c|c|c|c|c|c|}
\hline \multicolumn{7}{|c|}{ Wealth Index Quintile } \\
\hline \multirow[t]{2}{*}{ Quintiles } & \multicolumn{3}{|l|}{ Overall } & \multicolumn{3}{|c|}{ Families of children under-five (at least one) } \\
\hline & Frequency & Percentage & Cumulative \% & Frequency & percentage & Cumulative $\%$ \\
\hline Lowest & 48,469 & 19.7 & 19.7 & 5685 & 23.4 & 23.4 \\
\hline Second & 49,543 & 20.1 & 39.8 & 5133 & 21.1 & 44.5 \\
\hline Middle & 51,590 & 20.9 & 60.7 & 4988 & 20.5 & 65.1 \\
\hline Fourth & 50,823 & 20.6 & 81.3 & 4833 & 19.9 & 85 \\
\hline Highest & 46,076 & 18.7 & 100 & 3655 & 15 & 100 \\
\hline Total & 246,501 & 100 & - & 24,294 & 100 & - \\
\hline
\end{tabular}


Table 5 Wealth index quintile, by Region

\begin{tabular}{llllll}
\hline Region & \multicolumn{6}{l}{ Wealth Index Quintile (Row \%) } \\
\cline { 2 - 6 } & Lowest & Second & Middle & Fourth & Highest \\
\hline Southern & 40.9 & 21.7 & 16.6 & 12.6 & 8.2 \\
Central & 15.3 & 21.6 & 22.8 & 22.8 & 17.4 \\
Northern & 6.1 & 14.9 & 21.0 & 30.3 & 27.7 \\
\hline
\end{tabular}

all. The log odds of underweight decreased by $0.08,0.19$, 0.25 and 0.59 for children whose mothers got primary, middle, secondary and higher education respectively, compared to those having no education (Table 2).

The risk of underweight is significantly affected by father's occupation. Here, unemployed category is taken as a benchmark. The log odds of underweight are increased by 0.08 and 0.16 for the children whose fathers were officials and laborer respectively; in contrast, they decreased by 0.06 for child whose fathers were farmers and remained almost unchanged for children whose fathers owned any business entity (small or large) (Table 2).

Underweight status of Children under-five in Punjab is negatively correlated with household wealth index quintile. Going from the lowest wealth index quartile to second, middle, fourth and highest wealth index quantiles, decreases the $\log$ odds of underweight by $0.18,0.35,0.45$ and 0.83 respectively (Table 2).

Total number of children ever born to a woman is positively associated with the risk of underweight. Addition of every single child into the total number of children ever born to a woman increases the log odds of underweight by 0.04 (Table 2).

The household's access to improved sanitation facility decreases the log odds of underweight by 0.09 compared to unimproved sanitation facilities (Table 2).

Underweight status of children is inversely related to the age of their mothers. The risk of underweight found highest in the children whose mother's age was less than twenty years at time of their birth, and it decline down gradually as the age of mother increase. The spread of underweight is almost same for mother's age group of 20-42 years (when children born), relatively higher beyond this age group, and highest if mother age is grater then 45 years (Fig. 2).

Underweight status of children is directly but nonlinearly correlated with the age of children (in months) as shown in Fig. 3 and Table 3. It shows that underweight status of children is normal from birth up to about

Table 6 Urban-Rural distribution of sampled population, by Region

\begin{tabular}{lll}
\hline Region & Locality (Row \%) & \\
\cline { 2 - 3 } & Rural & Urban \\
\hline Southern & 72.3 & 27.7 \\
Central & 63.5 & 36.5 \\
Northern & 57.7 & 42.3 \\
\hline
\end{tabular}

12 months of age, then it gradually inclines and got severe after 18 months of age. This pattern continues until the age of 20 months and turn out to be almost static up to the age of about 42 months, afterward falls sharply. The prevalence of underweight is revealed to be more pronounced in age group of 18-32 months (Fig. 3).

Exposure of child's mother to mass media reduces the log odds of underweight by 0.02 in comparison with no access to media at all (Table 2).

Refer to Table 2, the prevalence of underweight is more noticeable in the Southern Punjab. Going from Southern Punjab to Central and Northern Punjab decreases the log odds of underweight by 0.09 and 0.39 .

The underweight status of children is slightly but not significantly affected by mother's occupation, source of drinking water and total number of under-five children in household (Table 2).

\section{Discussion}

This study is focused on various socioeconomic and demographic aspects of underweight prevalence among under-five children in Punjab province of Pakistan and may facilitate the concerned administration and policy makers in formulation of apt polices to address it.

However, it exclude others factors related to health of children and mothers such as birth interval, health status of mother during pregnancy, place of delivery, weight of a child at birth, exclusive breast feeding, vaccination status of children, child morbidity status (fever, measles, diarrhea and ARI), type of food he/she received, mother's BMI, maternal and eternal care and use of extra food during pregnancy etc. In addition, there are three commonly used measures of child nutritional status: Stunting (height-for-age), Wasting (weight-for-height) and Underweight (weight-for-age). For the sake of conciseness only the last mentioned has been used, in this study.

Since, quality, availability and accessibility of hygienic food, health care and other facilities (like water and sanitation, exposure to media etc.) are considerably lower in rural Punjab, therefore, the children from rural areas of Punjab found more like to be underweight than their urban counterparts. This finding is consistent with findings obtained by other authors [12, 14, 17].

Our finding discloses a strong positive association between underweight and education level of father and mother of children. It is because, the educated parents usually have more knowledge about diet and health of children. In addition, education may change their traditional beliefs about diseases and taking care of their children. It also found consistent with several other similar studies $[5,6,10,12,14-18]$. Furthermore, the risk of underweight is $18 \%$ lower in children whose mother possesses higher education than fathers with same educational qualification (Fig. 4). It might because, 
Table 7 Education Level of Mother and Father, by Region

\begin{tabular}{|c|c|c|c|c|c|c|c|c|c|c|}
\hline \multirow[t]{2}{*}{ Region } & \multicolumn{5}{|c|}{ Mother's Education (Row \%) } & \multicolumn{5}{|c|}{ Father's Education (Row \%) } \\
\hline & None & Primary & Middle & Secondary & Higher & None & Primary & Middle & Secondary & Higher \\
\hline Southern & 64.1 & 14.7 & 6.8 & 7.4 & 7.0 & 41.3 & 19.0 & 13.3 & 15.1 & 11.2 \\
\hline Central & 42.7 & 20.7 & 10.9 & 13.7 & 12.0 & 23.5 & 18.8 & 17.9 & 24.6 & 15.3 \\
\hline Northern & 28.0 & 19.8 & 13.2 & 18.9 & 20.1 & 10.4 & 14.0 & 22.4 & 33.0 & 20.2 \\
\hline
\end{tabular}

the mothers usually spend more time with children compared with their fathers.

The risk of underweight found more severe in children belongs to families with lowest wealth index quintile. Because, it is impossible for parents with a very small income to maintain the increasing need of food as well as health expenditures of children, which results undernourishment. On the other hand, wealthier parents are more likely to afford hygienic food, healthier living conditions and better health-care that improves the child nutrition and overall health. Many other studies on child nutrition illustrate the similar results [5, 10, 12-16].

Our study has found positive relationship between the number of children ever born to a woman and underweight prevalence. Same findings are revealed in a study carried out by Islam et al. (2013) [12]. Generally, the number of children ever born to a woman (fertility) have an inverse effect on child nutrition and health, which results the child to be underweight. It is because, families with more children, experience more economic strain for food consumption; hence, the children from these families are more likely to suffer from malnutrition and underweight. In addition, up to $40 \%$ of people in Punjab fall in 1 St and 2nd wealth index quintile, i.e. low-income quintiles (Table 4). Whereas, this percentage goes up to $45 \%$ for families with one or more children in household under-five year of age. Therefore, it is impossible, for such people to maintain their livelihood and fulfill their basic needs. Hence, addition of every newborn baby in family may further reduce the distribution of income on health and food of children, consequently the risk of underweight increase.

The underweight status of children found negatively associated with improvement in sanitation facilities. It is because, the improved sanitation reduces the risk of diseases; consequently, the risk of underweight is decreased. The source of drinking water revealed similar but

Table 8 Access to Mass Media and Sanitation, by Region

\begin{tabular}{llllll}
\hline Region & \multicolumn{2}{l}{ Sanitation (Row \%) } & & \multicolumn{2}{l}{ Access to Media (Row \%) } \\
\cline { 2 - 3 } \cline { 5 - 5 } \cline { 5 - 5 } & Unimproved & Improved & & No & Yes \\
\hline Southern & 44.5 & 55.5 & & 50.0 & 50.0 \\
Central & 29.8 & 70.2 & & 29.2 & 70.8 \\
Northern & 19.3 & 80.7 & 20.4 & 79.6 \\
\hline
\end{tabular}

comparatively lesser impact on underweight status of children. It might because, the $94 \%$ inhabitants of Punjab use improved source of drinking water while comparatively lesser proportion of population (66\%) use improved sanitation facility [1]. In addition, the improved source" indicator is based on the categorization of water supplies by type of facility and does not consider the direct measurements of water quality, i.e. the water from improved source is not necessarily be free from contaminants [23].

The underweight status of children is negatively associated with mother's access to media (Table 2). It could be because, the exposure to media may lead to educate the mothers about health and food of children as well as more effective allocation of income to devote on their health and nutrition. These results are consistent with findings obtained by other authors [12, 17].

Refer to Fig. 4, the underweight status of children is inversely related to age of mother when child born. The surprising result for the underweight status of children whose mother age is greater than forty years is probably due to smaller frequency of observations with very high dispersion among them. Mothers of only $2.8 \%$ of children had the age 40 years or more when they born as well as the variation among the risk of underweight relatively higher for this age group.

The reasons for nonlinear association of underweight status of children with their age are that: usually children born with approximately normal anthropometric status; but afterwards, the health status of the most children became worse due to different socio-economic and biological factors and until it improved and become stable at a low level. The highest risk of underweight during the age group of 18 32 months is might because, during the aforesaid age group, kids are usually weaned from breast as well as their mothers do lose their ability to produce enough milk to fulfill the nutritional requirement of growing children. These results are consistent with findings obtained by other authors $[10,11,14]$.

The causes for such a high rate of underweight prevalence in Southern Punjab Southern Punjab also called Seraiki belt (consisting of 11 districts) could be:

Firstly, Southern Punjab is more deprived region of province, $41 \%$ of people residing in this region have lowest wealth index quintile (Table 5). 
Secondly, 72\% of people living in Southern Punjab belongs to rural areas with poor health, living and educational facilities which is highest in entire province (Table 6).

Thirdly, the statistics of parent's education of under-five children is worse in Southern Punjab. In this region, $64 \%$ of mothers and $41 \%$ of fathers of under five children are illiterate (Table 7). This percentage is highest in entire province (Table 7).

Fourthly, $45 \%$ of the inhabitant of Southern Punjab have no access to improved sanitation which is also highest in entire province (Table 7).

Fifthly, about one-half of resident of this region has no access to mass media at all. It is not only highest compared with rest of Punjab but horrible to see in this era (Table 8).

In addition, Southern Punjab is considered as most deprived and neglected part of Punjab. Since 1970, South Punjab has not been receiving its due share from provincial resources. Development schemes for said region were diverted to Central and Northern parts of province. According to recent data, poverty and unemployment are relatively higher in this region [1, 3, 24-27]. Furthermore, unlike rest of Punjab province, People in Southern part of province, which are under the sway of powerful landed gentry and tribal sardars (Tribal chiefs), suffer from lack of opportunity to improve their livelihood.

Therefore, to-a-days, for fair distribution of resources and administrative reasons, the demand for creation of new autonomous province in south Punjab, i.e. Seraiki Province (Seraiki is a native language of this region), is under national debate and focus.

\section{Conclusion}

The results of this study reveal that the family's wealth index quintile, mother education level, father education level, geographical region, locality and total number of children ever born to a woman (fertility) are significantly associated with underweight status of children underfive in Punjab. The results from this study are found to be consistent with other studies $[6,8,11,13]$.

In order to achieve the sustainable development goal Punjab needs to scale up target-oriented programs such as poverty reduction income-generating interventions and improvement of education and health facilities for poor population and deprived parts of province especially Southern Punjab.

Recommendations for researchers:

There are three commonly used measures of child nutritional status: Stunting, Wasting and Underweight. Only the last-mentioned measure has been used in this study. Hence, Stunting and wasting may also be used for said purpose. In addition, this study is specific to Punjab province; same may be don for other provinces/parts of Pakistan.

\section{Supplementary Information}

Supplementary information accompanies this paper at https://doi.org/10. 1186/s12889-020-09675-5.

Additional file 1. Supplementary information 1 [27-33]

Additional file 2. Supplementary information 2 [34-38]

Additional file $\mathbf{3}$ : Figure B1 ACF for step $=1$.Auto correlation function plot at step $=1$ created through $\mathrm{R}$ language

Additional file 4 : Figure B2 ACF for step $=10$. Auto correlation function plot at step $=10$ created through $\mathrm{R}$ language

\section{Abbreviations}

ARI: Acute Respiratory IIIness; BMI: Body Mass Index; HH: Household; MDGS: Millennium Development Goals; MICS: Multiple Indicator Cluster Survey; NNS: National Nutrition Survey; UN: United Nations; UNICEF: United Nation Children's Emergency Fund; WHO: World Health Organization

\section{Acknowledgements}

Authors are thankful to Mr. Muhammad Amin and Syed Wasim Abbas for their support in managing data files and development of map. Authors are also thankful to the reviewers and editor for their efforts and expertise to refine this paper.

\section{Availability of data and material}

MICS 2014 dataset is publicly available online [26], public access to the data base is open and no ethical approval is required to access and use this data.

\section{Authors' contributions}

RF and MAK conceptualized the research topic and drafted its manuscript. RF mainly performed the data analysis. MK and HK significantly contributed to the writing process and interpretation. HK and MA revised the article critically and provided further inputs. RF and MAK finally structured the manuscript, collected the references and edited extensively before

finalization. All authors read and approved the final manuscript.

\section{Funding}

Not applicable.

Ethics approval and consent to participate

Not applicable.

\section{Consent for publication}

Not applicable.

\section{Competing interests}

The authors declare that they have no competing interests.

\section{Author details}

${ }^{1}$ Bureau of Statistics, Government of the Punjab Lahore, Lahore, Pakistan. ${ }^{2}$ Department of Statistics, GC University Lahore, Lahore, Pakistan.

${ }^{3}$ Department of Statistics, Faculty of Science, King Abdulaziz University, Jeddah 21551, Saudi Arabia.

Received: 24 April 2019 Accepted: 12 October 2020

Published online: 30 November 2020

\footnotetext{
References

1. MICS. Multipe Indicator cluster survey. Lahore: Punjab Bureau Of Statistics; 2014.

2. Unicef. The state of the World's children. New York: Oxford University Press; 1998. PDHS. (2012-13). Pakistan demographic and health survey.

4. The World Bank. (2015). http://data.worldbank.org/indicator/SH.STA.MALN.ZS. Retrieved November 24, 2015, from The World Bank: http://wnw.worldbank.org/.

5. Alasfoor, D., Traissac, P., Gartner, A., \& Delpeuch, F. (2007, September). Determinants of persistent underweight among children, aged 6-35 months, after huge economic development and improvements in health Services in Oman. J Health Popul Nutr, 25(3), :359-369.

6. Khan R, M. I., \& Hayat, M. S. Factors causing malnutrition among under-five children in Bangladesh. Pak J Nutr. 2006;5(6):558-62.
} 
7. Mengistu, K., Alemu, K., \& Destaw, B. (2013). Prevalence of malnutrition and associated factors among children aged 6-59 months at Hidabu Abote District, north Shewa, Oromia regional state. Gondar: Institute of Public Health, College of Medicine and Health Sciences, University of Gondar, Gondar, Ethiopia doi:https://doi.org/10.4172/2161-0509.T1-001.

8. Sapkota V, Gurung C. Prevalence and predictors of underweight, stunting and Waisting in under-five children. JNHR. 2009;7(15):120-6.

9. Wolde, T., Belache, T., \& Birhanu, T. (2014). Prevalence of Undernutrition and determinant factors among preschool children in Hawassa, Southern Ethiopia Food Science and Quality Management, 29.

10. Anderson A, Bignell W, Winful S, Soyiri I, Steiner-Asiedu M. Risk factors for malnutrition among children 5-years and younger in the Akuapim-North District in theEastern region of Ghana. Curr Res J. 2010;2(3):183-8.

11. Islam MM, Alam M, Tariquzaman M, Kabir MA, Pervin R. Predictors of the number of under-five malnourished children in Bangladesh: application of the generalized Poisson regression model. BMC Public Health. 2013;13(11) Retrieved from http://www.biomedcentral.com/1471-2458/13/11.

12. Kisiangani I, Mbakaya C, Mekokha A, Magu D. Prevelence of Malunaration among Preschool Children (6-59 months) in Westren Province, Kenya. J Public Health Epidimol. 2014;6(11):398-406. https://doi.org/10.5897/ JPHE2014.0660.

13. Lasisi KE, Adebayo S, Abdulhamid B. Analysis of Nigerian children underweight nutritional status using Geoadditive cox models with Gaussian and binomial links. Afr Dev Resourc Res Institut J. 2014;10(2) Retrieved from http://www.journals.adrri.org/.

14. Nzala S, Siziya S, Babaniyi O, Songolo P, Muula A, Rudatsikira E. Demographic, cultural and environment factors associated with frequency and severity of malnutrition among Zambian children less than five years of age. J Public Health Epidemiol. 2011;3(8):362-70 Retrieved from http://www. academicjournals.org.

15. Zewdu S. Magnitude and factors associated with malnutrition of children under-five years of age in rural Kebeles of Haramaya, Ethiopia. Harar Bull Health Sci. 2012:221-32.

16. Kandala, N.-B., Fahrmeir, L., Klasen, S., \& Priebe, J. (2008). Geo-additive models of childhood Undernutrition in three sub-Saharan African countries. University of Warwick. Retrieved from https://doi.org/10.1002/psp.524.

17. Lasisi KE, Nwaosu S, Abdulazeez KA. Geoadditive cox models with Gaussian and binomial links for the analysis of wasting status of Nigerian children. J Nat Sci Res. 2014:4.

18. Belitz, C. (2007). Model selection in generalised structured additive regression models. MÄunchen.

19. Fahrmeir K, Lang. Penalized structured additive regression for space-time ata: a Bayesian perspective. Stat Sin. 2004;14:731-61.

20. Kneib, \& Fahrmeir. (2005). Structured Additive Regression for Categorical Space-time Data: A mixed model approach. Biometrics, to appear.

21. Kneib, T. (2005). Mixed model based inference in structured additive regression. Munchen.

22. Unicef. (2015). Water and sanitation. Retrieved from Unicef: http://data. unicef.org/water-sanitation/water.html.

23. MICS. Multiple Indicator cluster survey. Lahore: Punjab Bureau Of Statistics; 2007.

24. MICS. (2011). Multiple Indicator cluster Srvey Punjab. Lahore: Punjab Bureau of Statistics.

25. NNS. (2011). National Nutrition Survey. Aga Khan University, Pakistan, Planing Comossion ,Planing and Development Division, Government of Pakistan.

26. Unicef. Retrieved from Unicef: http://mics.unicef.org/surveys.

27. Filmer D, Pritchett LH. Estimating wealth effects without expenditure data or tears: an application to educational enrolments in states of India. Demography. 2001;38(1):115-32.

28. Rutstein, S. (2008). The DHS wealth index: approaches for rural and urban areas. Demographic and Health Research Division, Macro International Inc.

29. Rutstein, S., \& Johonson, K. (2004). The DHS wealth index. DHS comparative reports no. 6. Calverton, Maryland: ORC macro, MEASURE DHS.

30. Cheema A, Khalid L, Patnam M. The geography of poverty: evidence from the Punjab. Lahore J Econ. 2008:163-88.

31. Gazdar, H. (1999). Review of Pakistan Poverty Data, Monograph Series \# 9. Sustainable Development Policy Institute Islamabad.

32. Jamal H. The Punjab indices of multiple Depriviation 2003-04 and 2007-08. Lahore: Planing \& Development Deportment, Government of Punjab; 2011.

33. Malik, S. J. ( 2005). Agricultural growth and rural poverty: review of the evidence. Asian Development Bank.
34. Brezger K, Lang. Bayes X: analyzing Bayesian structured additive regression models. J Stat Softw. 2005;14(11).

35. Sahlin K. Estimating convergence of Markov chain Monte Carlo simulations. Sweden: Mathematical Statistics, Stockholm University; 2011.

36. Brooks, S. P., \& Roberts, G. O. (1998). Convergence assessment techniques for Markov chain Monte Carlo. Kluwer academic publishers, Dordrecht NL3300 AA Netherlands.

37. Cowles MK, Carlin BP. Markov chain Monte Carlo convergence diagnostics: a comparative review. J Am Stat Assoc. 1996;91:883-904.

38. Plummer, M., Best, N., Cowles, K., \& Vines, K. (2010). Coda:Convergence diagnosis and output analysis for MCMC.

\section{Publisher's Note}

Springer Nature remains neutral with regard to jurisdictional claims in published maps and institutional affiliations.
Ready to submit your research? Choose BMC and benefit from:

- fast, convenient online submission

- thorough peer review by experienced researchers in your field

- rapid publication on acceptance

- support for research data, including large and complex data types

- gold Open Access which fosters wider collaboration and increased citations

- maximum visibility for your research: over $100 \mathrm{M}$ website views per year

At BMC, research is always in progress.

Learn more biomedcentral.com/submissions 